\title{
Improving the Method of Blasting Parameters Calculation in Construction of Horizontal and Inclined Excavation, for Example Mines of the Polar Division "Norilsk Nickel"
}

\author{
Alexander A. Kirsanov*, \\ Sergey A. Vokhmin and George S. Kurchin \\ Siberian Federal University \\ 79 Svobodny, Krasnoyarsk, 660041, Russia
}

Received 10.02.2014, received in revised form 28.03.2015, accepted 04.04.2015

The article is devoted to the task today to improve the effectiveness of blasting during construction of horizontal and inclined mine workings. Proposed method for calculating the parameters of blasting during mining, which is based on the reliable determination of the main areas of action of the explosion.

Keywords: Blasting and drilling technology, method of calculation, the charge hole, explosion, burn cut.

\section{Совершенствование методики расчета параметров буровзрывных работ при строительстве горизонтальных \\ и наклонных горных выработок на примере рудников ЗФ ОАО ГМК «Норильский никель»}

\author{
А.К. Кирсанов, С.А. Вохмин, Г.С. Курчин \\ Сибирский федеральный университет \\ Россия, 660041, Красноярск, пр. Свободный, 79
}

Статья посвящена актуальной на текущчий момент задаче повышения эффективности буровзрывных работ при строительстве горизонтальных и наклонных подземных горных выработок. Предложена методика расчёта параметров буровзрывных работ при проведении горных выработок, базирующаяся на достоверном определении основных зон действия взрыва.

Ключевые слова: буровзрывные работыл, методика расчёта, заряд, ипур, взрыв, прямой вруб.

(C) Siberian Federal University. All rights reserved

* Corresponding author E-mail address: aka_sancho@mail.ru 


\section{Введение}

Строительство новых и реконструкция действующих шахт и рудников требуют выполнения большого объёма работ по проведению горных выработок, протяжённость которых только по одному предприятию достигает десятков километров.

До настоящего времени на большинстве рудников строительство выработок ведется с применением буровзрывных работ (БВР). Совершенствование БВР является одним из направлений повышения эффективности проведения выработок. В зависимости от того, насколько корректно рассчитаны параметры БВР, могут существенно изменяться технико-экономические показатели проходки горной выработки.

\section{Постановка задачи и методика исследований}

При строительстве горизонтальных и наклонных горных выработок буровзрывные работы должны обеспечить заданные размеры и форму сечения выработки, точное её оконтуривание, качественное дробление породы и сосредоточенный отброс её от забоя, а также высокий коэффициент использования шпуров (КИШ).

На сегодняшний день большинство существующих методик расчёта параметров БВР представляют собой сложные эмпирические формулы, расчёт которых базируется на первоочередном определении удельного расхода взрывчатого вещества (BВ). Недостатком этого подхода является использование в формулах расчёта удельного расхода ВВ коэффициентов, имеющих весьма широкий диапазон изменения, и принимаемые значения чаще зависят от уровня подготовки специалиста, выполняющего расчёты. В результате параметры БВР определяют по усредненным значениям, что отрицательно сказывается на эффективности взрывных работ.

В соответствии с вышеизложенным возникает задача поиска иного подхода к расчёту параметров БВР и разработки соответствующей методики.

В основу предлагаемой методики положено определение радиусов зоны смятия и трещинообразования согласно «новой теории разрушения горных пород удлинёнными зарядами ВВ», разработанной Б.Н. Кутузовым [1].

Установлено, что при взрыве цилиндрического заряда ВВ в массиве образуется две зоны: зона смятия и зона трещин [2] (рис. 1).

Предлагаемая методика определения параметров БВР основана на достоверном определении радиусов двух этих зон и предполагает выполнение расчётов в такой последовательности:

1. В зависимости от горно-геологических и горно-технических условий выявляются показатели:

- величина радиуса зоны смятия определяется по формуле [1]

$$
R_{c M}=d \sqrt{\frac{\rho \cdot D^{2}}{8 \cdot f \cdot 10^{7}}}, \mathrm{M},
$$

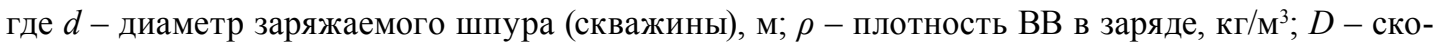
рость детонации применяемого ВB, м/с; $f$ - коэффициент крепости пород по шкале М.M. Протодьяконова;

$$
-397-
$$




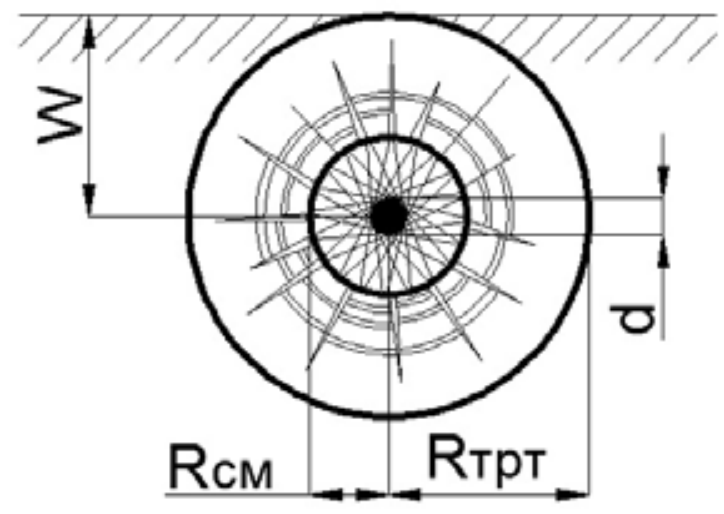

Рис. 1. Схема формирования радиуса зоны смятия и радиуса зоны трещинообразования: $\mathrm{d}-$ диаметр заряжаемого шпура (скважины); Rсм - радиус зоны смятия; Rтр - радиус зоны трещинообразования; $\mathrm{W}$ - линия наименьшего сопротивления

- радиус зоны трещинообразования [1]:

$$
R_{m p m}=0.2102 \cdot d \cdot \rho^{0.75} \cdot D^{1.5} \cdot \sigma_{c \mathcal{~}}^{-0.25} \cdot \tau_{c p}^{-0.5} \cdot K_{c}^{-0.5}, \mathrm{M},
$$

где $\sigma_{c ж}-$ предел прочности пород на сжатие, Па; $\tau_{c p}$ - предел прочности пород на срез, Па; $K_{c}-$ коэффициент структурного ослабления;

- коэффиииент структурного ослабления согласно исследованиям [3] можно определить по формуле

$$
K_{C}=0,64 \cdot L_{T}-0,115 \cdot L_{T}^{2}+0,086,
$$

где $L_{T}$ - расстояние между трещинами (при $\mathrm{Lr}>2,5$ коэффициент структурного ослабления принимаем равным 1,0 );

- линия наименьшего сопротивления [1]:

$$
W=R_{m p m} \cdot \cos (0,5 \cdot \alpha), \mathrm{M},
$$

где $\alpha$ - минимальный угол образующейся взрывной воронки $\alpha=60^{\circ}$.

Однако в этих формулах скорость детонации принимается по усредненным значениям, что отрицательно влияет на точность расчёта параметров БВР. Рассмотрим взаимосвязь скорости детонации, диаметра заряжаемого шпура и плотности заряжания с точки зрения оптимизации этих параметров.

В результате исследований зарубежных учёных [4-6] детонационной способности промышленных ВВ было установлено, что их детонационные характеристики напрямую связаны с диаметром заряжаемого шпура и плотности ВВ. На рис. 2 приведены зависимости, определенные зарубежными исследователями применительно к аммиачноселитренным ВВ.

Процессы взрывчатого превращения могут протекать с различной скоростью и существенно отличаться по своему характеру, что мы и можем наблюдать на рис. 2. Для более корректного определения скорости детонации необходимо учитывать ряд факторов в совокупности друг с другом. 


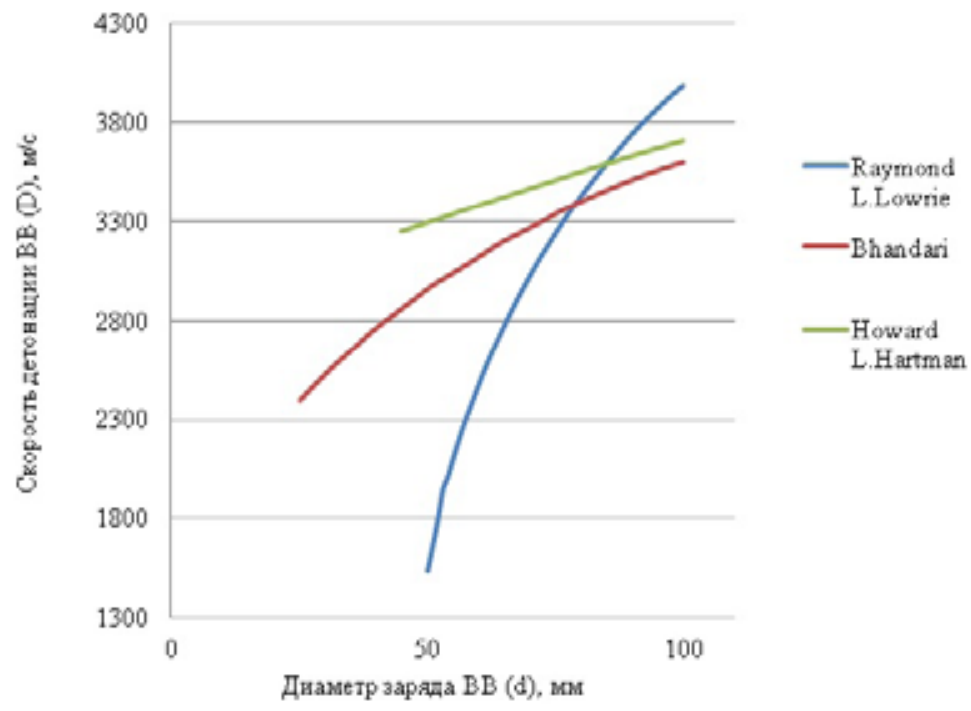

Рис. 2. Влияние диаметра заряда (d) на скорость детонации (D)

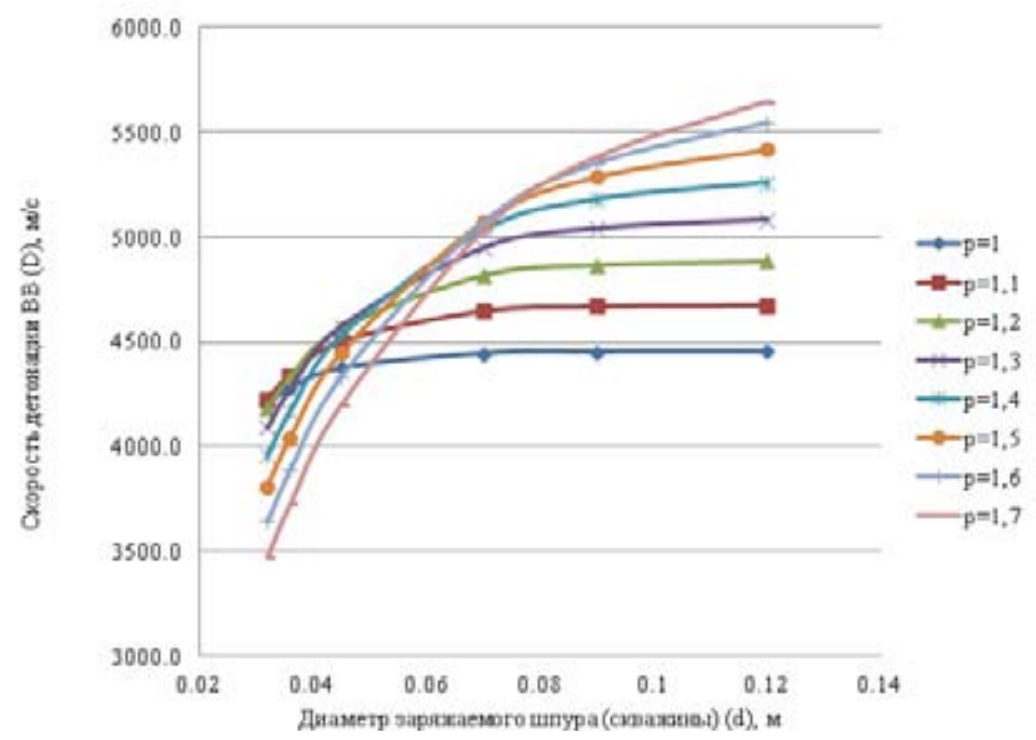

Рис. 3. Влияние диаметра заряда на скорость детонации с учетом плотности заряжания

Исследованиями С.А. Калякина и К.Н. Лабинского [7] установлено, что на скорость детонации аммиачн-селитренных ВВ оказывает влияние не только диаметр заряда, но и плотность заряжания. На рис. 3 изображены зависимости, полученные с учётом данных, приведенных в работе [7].

Расчёт скорости детонации аммиачно-селитряных ВВ с учётом влияния диаметра заряда и плотности ВВ производится по формуле

$$
\begin{gathered}
D=(11,794 \cdot \rho-7080) \cdot d^{0,00057 \cdot p-0,46}, \mathrm{~m} / \mathrm{c} . \\
-399-
\end{gathered}
$$


Подставив формулу (5) определения скорости детонации для аммиачно-селитренных ВВ в выражения (1) и (2), получим формулы для определения радиусов зон смятия и трещинообразования:

$$
\begin{aligned}
& R_{c M}=d \sqrt{\frac{\rho \cdot\left((11,794 \cdot \rho-7080) \cdot d^{0,00057 \cdot \rho-0,46}\right)^{2}}{8 \cdot f \cdot 10^{7}}}, \text { м. } \\
& R_{m p m}=0.2102 \cdot d \cdot \rho^{0.75} \cdot\left((11,794 \cdot \rho-7080) \cdot d^{0,00057 \cdot \rho-0,46}\right)^{1.5} \cdot \sigma_{c \mathcal{M}}^{-0.25} \cdot \tau_{c p}^{-0.5} \cdot K_{c}^{-0.5}, \mathbf{M .} .
\end{aligned}
$$

2. Если знать результаты всех этих расчётов, можно начать графическое построение фронтальной проекции паспорта БВР, начинающееся с расстановки оконтуривающих шпуров. Для этого на расстоянии $R_{c M}$ от контура выработки определяют точку расположения первого шпура (рис. 4).

После этого на расстоянии $R_{c м}$ от проектного контура по всему периметру выработки располагают остальные оконтуривающие шпуры. Расстояние между оконтуривающими шпурами определяется величиной зоны трещинообразования $R_{m p m}$ (рис. 5а). При этом, если забой заряжается разными $\mathrm{BB}$, зона $R_{\text {mpm }}$ определяется для каждого типа заряда ВВ отдельно (рис. 5б).

Если число шпуров при их расстановке оказывается не целым, то его округляют в большую сторону до ближайшего целого числа шпуров, а расстояние между шпурами пересчитывают так, чтобы расстояния между оконтуривающими шпурами, работающими в одинаковых

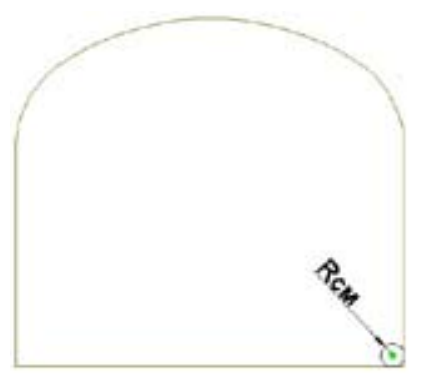

Рис. 4. Схема расположения первого шпура

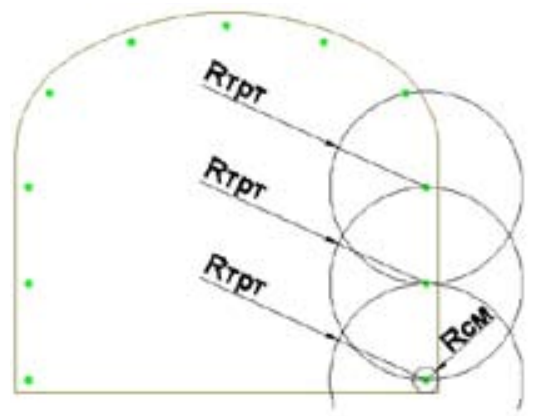

a

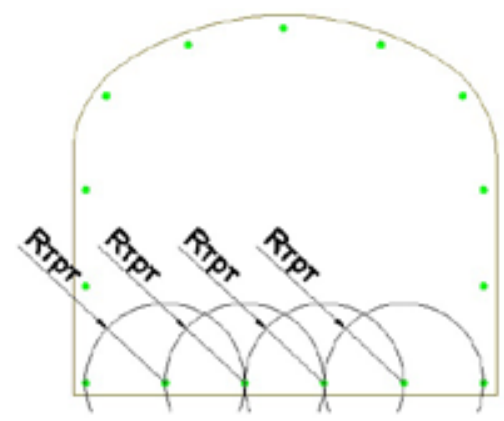

6

Рис. 5. Схема расположения оконтуривающих шпуров: а - расстановка оконтуривающих шпуров; б - расстановка оконтуривающих шпуров по почве с учетом разного типа ВВ 


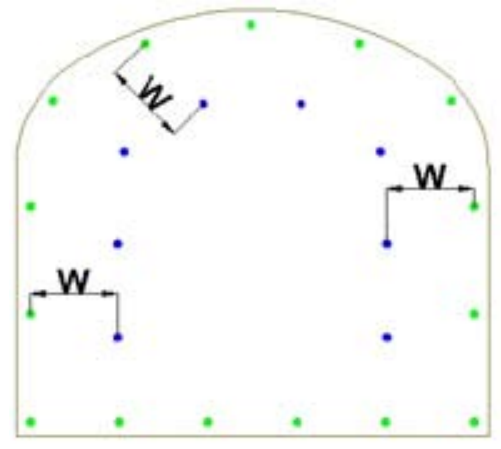

a

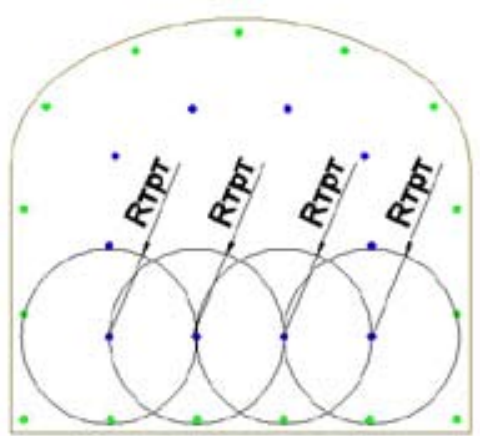

6

Рис. 6. Схема расположения первого ряда вспомогательных шпуров: а - расстановка первого ряда вспомогательных шпуров; б - расстановка первого ряда вспомогательных шпуров по почве с учетом разного типа $\mathrm{BB}$

условиях, были равными. Изменение расстояния от расчётного параметра допустимо не более чем на $\pm 10 \%$.

Расстояние между оконтуривающими и первым рядом вспомогательных шпуров определяется величиной линии наименьшего сопротивления (ЛНС) (рис. 6а). Расстояние между вспомогательными шпурами по горизонтали равно величине зоны трещинообразования (рис. 6б).

Если число шпуров при расстановке их по линии оказывается не целым, то его также округляют до ближайшего целого числа шпуров, а расстояние между шпурами пересчитывают так, чтобы расстояния были равными. Изменение расстояния от расчётного параметра допустимо в пределах $\pm 10 \%$.

С учетом этих параметров определяют расположение оконтуривающих и вспомогательных шпуров по сечению выработки.

3. Формирование врубовой полости является весьма важным элементом при взрывной отбойке. Эффективное взрывание невозможно без качественно оформленного взрывного вруба, поскольку в забоях с одной открытой поверхностью, чтобы получить высокий коэффициент использования шпура (КИШ) при буровзрывной технологии проведения выработок, необходимо создать вторую открытую поверхность. Эту функцию и выполняют врубовые шпуры.

Как показала практика ведения горных работ на рудниках ЗФ ОАО «ГМК «Норильский никель», наиболее эффективными врубами, позволяющими обеспечить высокий КИШ и необходимую скорость проходки, являются прямые врубы в сочетании с компенсационными (незаряжаемыми) скважинами. Это обусловлено тем, что применение такого типа врубов наиболее эффективно при бурении самоходными буровыми установками (СБУ) на глубину более $2 \mathrm{~m}$.

Количество компенсационных скважин и врубовых шпуров зависит от горногеологических условий и площади поперечного сечения проводимой горной выработки. Наиболее распространенные диаметры компенсационных скважин 76 и 102 мм, при этом их число изменяется от 1 до 4 шт. В отдельных случаях применяют компенсационные шпуры в количестве от 3 до 6 шт., диаметр их, как правило, такой же, как и заряжаемых шпуров.

$$
-401-
$$


Совокупность всего обилия факторов, влияющих на конструкцию заряда, число и схему расположения шпуров, обусловливает возникающие противоречия между различными авторами и предлагаемыми ими методиками расчёта взрывного вруба.

Стоит отметить, что при взрыве шпуровых зарядов нередки случаи отказов в передаче детонации или неполных взрывов с последующим воспламенением и выгоранием недетонировавших патронов [8]. Такой неполный взрыв может стать образованием так называемых стаканов. Это явление отчасти можно объяснить слишком близким расположением шпуров и вследствие этого повреждением соседних зарядов, взрываемых с замедлением.

Предлагаемый авторами метод расчёта конструкции прямого вруба учитывает все эти особенности и состоит из нескольких операций, выполняемых в такой последовательности:

В зависимости от условий отбойки вруб располагают по центру или смещают от оси выработки (вправо или влево). Затем производят расчёт параметров взрывного вруба и его построение (рис. 7; рис. 8а):

- определяют число компенсационных шпуров (скважин) во врубе:

$$
N_{0}=\frac{0,5 \cdot l_{0}-0,2 \cdot d_{0} \cdot l_{0}^{2}+1,3}{d_{0} \cdot 0,087}, \text { шт., }
$$

где $\mathrm{l}_{0}$ - длина компенсационного шпура (скважины), м; $\mathrm{d}_{0}$ - диаметр компенсационного шпура (скважины), м;

- рассчитывают расстояние между компенсационными шпурами (скважинами) вруба:

$$
h=d_{0}+d-\frac{\pi \cdot d^{2}}{12 \cdot d_{0}}, \mathrm{M}
$$

- расстояние между компенсационным и заряжсаемым шпурами вруба составляет $(2 \div 3) d_{0}$;

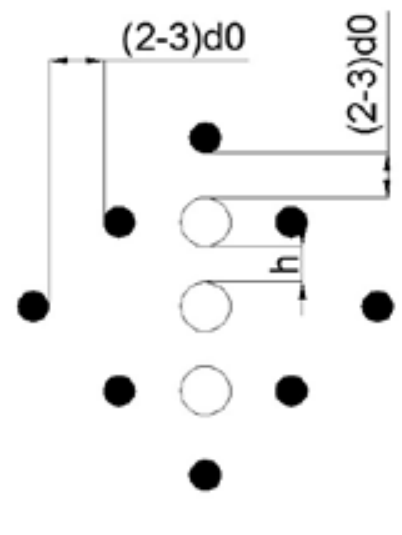

a
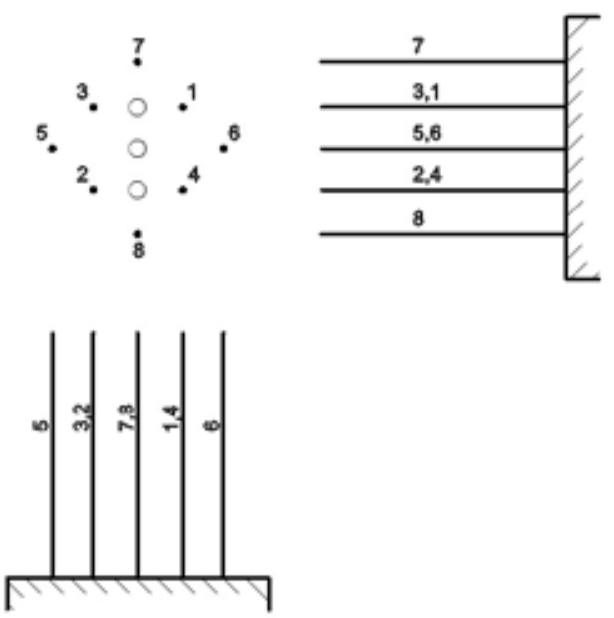

6

Рис. 7. Схема расположения компенсационных скважин и заряжаемых шпуров вруба: а - схема построения взрывного вруба по выведенным формулам; б - схема расположения взрывного вруба в забое 


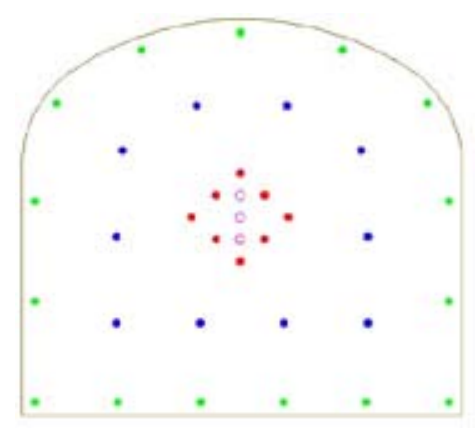

a

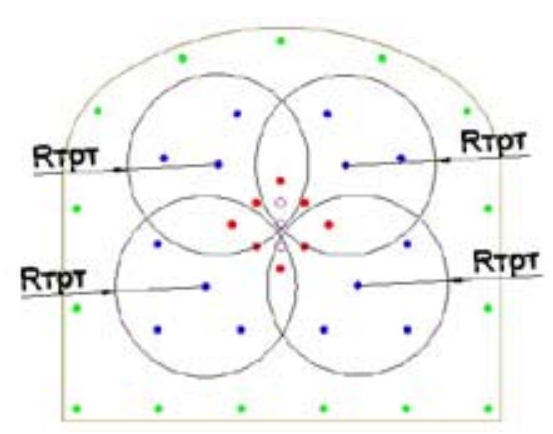

б

Рис. 8. Схема расположения комплекта шпуров при проходке горной выработки: а - схема расположения врубовых шпуров; б - схема расположения второго ряда оконтуривающих шпуров

- число заряжаемых врубовых шпуров

$$
N_{\theta p}=\frac{0,04 \cdot S \cdot k_{v}}{\pi R_{c M}^{2}}, \text { шт., }
$$

где $S$ - площадь поперечного сечения, ${ }^{2} ; k_{v}$ - коэффициент, учитывающий вязкость пород.

Глубина врубовых шпуров определяется возможностями технологического оборудования и, как правило, равна длине штанги. Глубина оконтуривающих и вспомогательных шпуров меньше врубовых примерно на 5-15\%.

Если одного ряда вспомогательных шпуров недостаточно и имеются участки, которые могут быть не проработаны, на расстоянии $R_{m p m}$ располагают второй ряд вспомогательных шпуров (рис. 8б).

И, наоборот, в случае малого сечения выработки вспомогательные шпуры могут полностью отсутствовать.

4. Расчёт конструкции шпуровых зарядов:

- длина заряда в шпуре определяется по формуле

$$
L_{3}=l_{u}-0,5 W-l_{\text {заб }}-l_{\sigma}, \mathrm{M},
$$

где $l_{u}$ - глубина шпура, м; $l_{\text {заб }}$ длина забойки, м; $l_{\sigma}$ - длина патрона-боевика, м;

- масса заряда в одном шпуре определяется по формуле

$$
Q_{3}=\frac{L_{3} \cdot \pi \cdot d^{2} \cdot \rho}{4}, \mathrm{\kappa} \Gamma
$$

- строится конструкция зарядов для каждого варианта и типа ВВ (рис. 9).

После произведения всех необходимых расчётов и расстановки шпуров по полученным значениям графическая часть паспорта БВР будет выглядеть следующим образом (рис. 10).

\section{Результаты исследований}

На основе вышеизложенной методики авторами были разработаны паспорта БВР и проведены опытные взрывы на рудниках ЗФ ОАО «ГМК «Норильский никель».

$$
-403-
$$




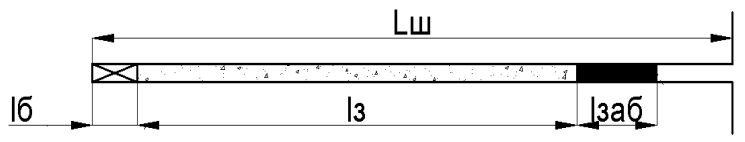

Рис. 9. Схема построения конструкции заряда

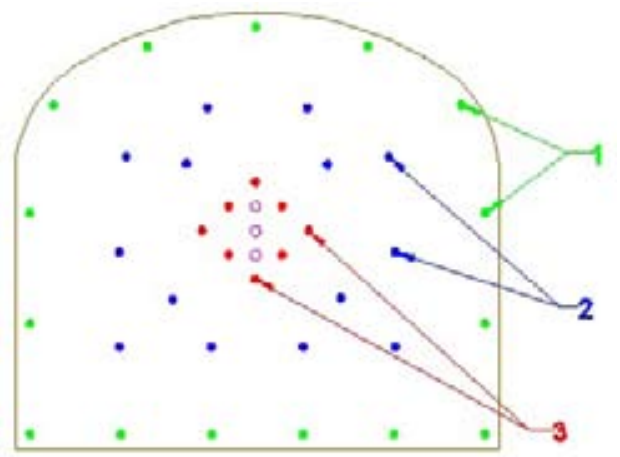

Рис. 10. Принципиальная схема расположения комплекта шпуров в забое: 1 - оконтуривающие шпуры; 2 - вспомогательные шпуры; 3 - врубовые шпуры

Таблица 1. Основные параметры двух паспортов БВР

\begin{tabular}{|l|c|c|}
\hline \multicolumn{1}{|c|}{ Показатель } & $\begin{array}{c}\text { Паспорт БВР, } \\
\text { используемый на } \\
\text { руднике }\end{array}$ & $\begin{array}{c}\text { Паспорт БВР опытного } \\
\text { взрыва }\end{array}$ \\
\hline Общее количество шпуров, шт. & 48 & 36 \\
\hline Количество врубовых шпуров, шт. & 12 & 12 \\
\hline Количество вспомогательных шпуров, шт. & 16 & 14 \\
\hline Количество оконтуривающих шпуров, шт. & 20 & 198,0 \\
\hline $\begin{array}{l}\text { Расход ВВ, кг.: } \\
\text { Гранулит АС-8 } \\
\text { Аммонит №6 ЖВ }\end{array}$ & 280,0 & 26,75 \\
\hline Объем бурения, шп. м & 39,25 & 181,0 \\
\hline
\end{tabular}

В табл. 1 приведены для сравнения параметры действующего и опытного паспортов БВР для условий шахты «Скалистая» рудника «Комсомольский»: диаметр шпуров 48 мм; применяемое буровое оборудование - СБУ типа Boomer M2D; крепость пород по шкале проф. М.M. Протодьяконова $\mathrm{f}=9$; сечение выработки 20,73 м; применяемое ВВ: гранулит $\mathrm{AC}-8$ и аммонит № 6 ЖВ.

Оценка качества взрывов по опытным паспортам БВР показала, что сечение выработки соответствует проектному, а дробление горной массы - предъявленным требованиям. При этом сократилось общее количество шпуров на 12 шт., что обеспечило уменьшение объёма бурения на 59 шп. м и снижение расхода гранулита АC-8 на 82,0 кг и 12,5 кг - аммонита № 6 ЖВ при одновременном увеличении коэффициента использования шпуров до 0,95-0,97. 


\section{Заключение}

Технология ведения БВР в современном мире должна базироваться на обоснованных и прошедших экспериментальную проверку методиках и расчётах для обеспечения максимальной эффективности отбойки при минимальных затратах.

Предлагаемая методика расчёта параметров БВР при проходке горных выработок в части сокращения числа шпуров, объемов бурения и удельного расхода ВВ прошла апробацию на восьми подземных рудниках ЗФ ОАО «ГМК «Норильский никель», где результаты проведенных взрывов показали работоспособность и эффективность предлагаемой методики.

\section{Список литературы}

[1] Кутузов Б.Н., Андриевский А.П. Новая теория и новые технологии разрушения горных пород удлиненными зарядами взрывчатых веществ. Новосибирск: Наука, 2002. 96 с.

[2] Кутузов Б.Н. Методы ведения горных работ. Ч.1. Разрушение горных пород взрывом: М.: Горная книга, 2007. 471 с.

[3] СНиП II-94-80. Подземные горные выработки. 1982. 37 с.

[4] Sushil Bhandari. Engineering rock blasting operations. Rotterdam, 1997. P. 375.

[5] Raymond L.Lowrie. Mining Reference Handbook. Published by the Society for Mining, Metallurgy, and Exploration, Inc. 2002. P. 448.

[6] Howard L.Hartman // SME Mining Engineering Handbook. 2nd Edition, 1992. Vol. 1. P. 2268.

[7] Калякин С.А., Лабинский К.Н. // Вісник КДПУ імені Михайла Остроградського. 2009. Вып. 6. С. 159.

[8] Станюкович К.П., Баум Ф.А., Шехтер Б.И. Физика взрыва. М., 1959. 800 с. 